\title{
Myocardial infarction, ischaemic stroke and pulmonary embolism before and after breast cancer hospitalisation
}

\author{
A population-based study
}

\author{
Myrthe P. P. van Herk-Sukel'; Sumitra Shantakumar2; Pieter W. Kamphuisen ${ }^{3}$; Fernie J. A. Penning-van Beest ${ }^{1}$; Ron M. C. Herings ${ }^{1,4}$ \\ ${ }^{1}$ PHARMO Institute for Drug Outcomes Research, Utrecht, the Netherlands; ${ }^{2}$ GlaxoSmithKline, Oncology Biometrics and Epidemiology, Research \& Development, RTP, North \\ Carolina, USA; ${ }^{3}$ Department of Vascular Medicine, Academic Medical Centre, Amsterdam, the Netherlands; ${ }^{4}$ Department of Health Policy \& Management, Erasmus University \\ Medical Centre, Rotterdam, the Netherlands
}

\begin{abstract}
Summary
We studied the occurrence of myocardial infarction (MI), ischaemic stroke (IS) and pulmonary embolism (PE) before and after breast cancer hospitalisation compared with cancer-free controls. For this, women with a first breast cancer hospitalisation during 2000-2007 were selected from the PHARMO Record Linkage System, including drug use and hospitalisations of three million inhabitants in the Netherlands, and matched $1: 10$ by age to cancer-free women. The occurrence of Ml, IS and PE were assessed in the 12 months before and after breast cancer hospitalisation. The study included 11,473 breast cancer patients, with a mean $( \pm S D)$ age of $59( \pm 14)$ years. Breast cancer patients were two to three times as likely as their cancer-free controls to have had a hospitalisation for $\mathrm{PE}, \mathrm{MI}$ or IS in the 12 months before diagnosis, though prevalence was $<1 \%$ in all groups. Breast cancer patients experienced an extreme high risk of PE in the first six months after diag-
\end{abstract}

nosis (hazard ratio [HR] 23.5, 95\% confidence interval [Cl] 11.1-49.7 compared to controls), which declined gradually to a four times increased risk (HR 3.6, 95\% $\mathrm{Cl}$ 2.4-5.5) more than 12 months after breast cancer hospitalisation. However, incidence was low: less than five events per 1,000 person years during all time periods. For MI and IS we did not observe significant increased HRs after breast cancer hospitalisation compared to controls. Breast cancer patients seem to have a higher risk profile to develop $\mathrm{MI}$ and $\mathrm{IS}$, and receive treatment that increases the risk of PE compared to cancer-free controls, although the frequency of hospitalisations was low.

\section{Keywords}

Breast cancer, incidence, ischaemic stroke, myocardial infarction, pulmonary embolism, risk factors

Financial support:

This study was supported by GlaxoSmithKline, RTP, NC, USA.

Received: December 7, 2010

Accepted after major revision: March 25, 2011

Prepublished online: May 26, 2011

doi:10.1160/TH10-12-0778

Thromb Haemost 2011; 106: 149-155

\section{Introduction}

The association between cancer and thrombosis, especially venous thrombosis, is well recognised (1-3). Cancer patients are at increased risk for thromboembolic complications due to the release of procoagulants, compression or invasion of blood vessels, or as a result of prolonged immobilisation, surgery or treatment with chemotherapeutic agents (3-6). Several studies suggest that the frequency of thromboembolism in cancer patients, especially pulmonary embolism (PE), is increasing $(6,7)$. This is alarming as thrombotic complications among cancer patients are associated with decreased survival $(8,9)$.

While the rate of venous thromboembolism (VTE) among cancer patients has been determined in several retrospective cohort studies $(6-8,10-14)$, published epidemiologic data on the incidence of the specific types of venous and arterial thromboem- bolism (15) is scarce. Moreover, as the risk of thrombosis varies within the cancer patient during the course of malignancy (1) timing of the occurrence of thrombotic events needs further research. This study focused on the occurrence of specific thromboembolic events in different time intervals among women with a hospitalisation for breast cancer. Although reported rates of VTE among breast cancer patients are one of the lowest among cancer patients (6-8), this highly prevalent cancer can contribute significantly to the overall burden of venous thromboembolism (14). We studied the more serious and well-defined venous and arterial thromboembolic events, which are myocardial infarction (MI), ischaemic stroke and PE. All three will result directly in a hospitalisation and may contribute significantly to the risk of mortality among breast cancer patients. The rates of these three events were determined before and after breast cancer hospitalisation and compared with cancer-free controls. In addition, risk factors for 
developing MI, ischaemic stroke and PE after breast cancer hospitalisation were defined.

\section{Methods}

\section{Data source}

Data were obtained from the PHARMO Record Linkage System (PHARMO RLS) which consists of multiple observational databases linked on a patient level, covering three million inhabitants of geographic defined areas in the Netherlands. Databases relevant for this study include the Dutch National Medical Register (LMR) (16) and the community pharmacy database (out-patient). The hospital records contain detailed information concerning admissions for more than 24 hours (h) and admissions for less than $24 \mathrm{~h}$ for which a bed is required, including primary and secondary diagnoses, procedures and dates of hospital admission and discharge. All diagnoses are coded according to the International Classification of Diseases, Ninth Revision, Clinical Modification (ICD9-CM). The drug dispensing histories from community pharmacies contain data on the dispensed drug, prescriber, dispensing date, amount dispensed, prescribed dose regimens, and thus the duration of use. All drugs are coded according to the Anatomical Therapeutic Chemical (ATC) Classification.

\section{Study population}

New hospitalised breast cancer women (ICD-9-CM code: 174) in the period from January $1^{\text {st }} 2000$ to December $31^{\text {st }} 2007$ were selected from the Dutch National Medical Register of the PHARMO RLS. Date of first breast cancer hospitalisation was defined as the cohort entry date and patients with any cancer hospitalisation (ICD-9-CM codes: 140-239) in the period of 10 years before the cohort entry date (or as far as history was available in the Dutch National Medical Register of the PHARMO RLS) were excluded. To be able to define co-morbidities in recent history based on drug use - next to hospitalisations, patients needed to have at least 12 months of history in the community pharmacy database of the PHARMO RLS. All patients were followed from cohort entry until end of data-collection in the PHARMO RLS (i.e. the patient moves out of the PHARMO RLS catchment area), death, or end of the study period (December $31^{\text {st }} 2008$ ), whichever occurred first.

\section{Cancer-free controls}

Controls were selected from all women included in the PHARMO RLS; a large, population-based cohort of cancer and cancer-free patients with thorough and unbiased information on medications and hospitalisations. The selection of the control cohort was step- wise. First, for each breast cancer patient we matched randomly 1:20 by age with breast cancer-free women (i.e. never hospitalised for breast cancer [ICD-9-CM code: 174]). Each of these potential controls was assigned the cohort entry date of the cancer patient case match. Second, we eliminated from the pool of 20 possible controls per case, any control that did not have 12 months of history before cohort entry date in the PHARMO RLS and/or who had a hospitalisation with a primary diagnosis for any cancer (ICD-9-CM codes: 140-239) in the period from 10 years before the cohort entry date (or as far as history is available in the Dutch National Medical Register of the PHARMO RLS) until December $31^{\text {st }} 2008$. Finally, out of the remaining controls that fulfilled the above criteria, ten per case were randomly selected and included in the control cohort.

\section{Outcomes}

Only thromboembolic events that are likely to lead to a hospitalisation were included in this study and selected by using primary discharge diagnosis codes: MI (ICD-9-CM: 410)(17), ischaemic stroke (ICD-9-CM: 433, 434, 437.1)(18, 19) and PE (ICD-9-CM: $415.1)(20,21)$. These three events were defined in 12 months of history and during follow-up (0-6 months, 6-12 months and 12 months to total follow-up).

\section{Patient characteristics}

The following characteristics were determined: age, duration of follow-up and use of the following cardiovascular drugs in the year before cohort entry based on ATC codes: platelet aggregation inhibitors (B01AC), other antithrombotic drugs (including aspirin, B01A excl. B01AC), lipid-lowering drugs (C10), antihypertensives (C02, C03 [excl. C03C], C07, C08, C09 [excl. C09X]), other cardiovascular drugs (e.g. antiarrhytmics, vasodilators and vasoprotectives; $\mathrm{C} 01, \mathrm{C} 04, \mathrm{C} 05)$ and antidiabetic drugs (A10). In addition, in the six months after cohort entry we also determined the use of chemotherapy based on hospital discharge diagnoses (ICD-9-CM code: V58.1) and/or oral chemotherapies supplied by community pharmacies (ATC code: L01 excl. targeted drug therapies: L01XC and L01XE), antineoplastic hormonal therapy (L02), breast cancer-related surgery (hospital procedure codes: 5-860 to 5-869, 5-870 to 5-879 and 5-400 to 5-409) and cumulative duration of any hospital stay $(0-10,>10$ days $)$.

\section{Analyses}

Prior drug use was compared between breast cancer patients and their controls using the Chi-square test. Prevalence proportions in the 12 months before cohort entry were assessed for each throm- 
Table 1: Age and prior drug use of breast cancer patients and cancer-free controls.

\begin{tabular}{|l|l|l|}
\hline & $\begin{array}{l}\text { Patients with breast cancer } \\
(\mathrm{N}=11,473)\end{array}$ & $\begin{array}{l}\text { Cancer-free control cohort } \\
(\mathrm{N}=114,730)\end{array}$ \\
\cline { 2 - 3 } & $\mathbf{N}(\%)$ & $\mathbf{N}(\%)$ \\
\hline Age in years (mean \pm SD) & $59( \pm 14)$ & $59( \pm 14)$ \\
\hline $\begin{array}{l}\text { Prior drug use } \\
\text { 1,2 }\end{array}$ & & $7,912(7)$ \\
\hline Platelet aggregation inhibitors & $1,166(10)$ & $2,684(2)$ \\
\hline Other antithrombotic drugs & $524(5)$ & $8,765(8)$ \\
\hline Lipid-lowering drugs & $1,292(11)$ & $23,353(20)$ \\
\hline Antihypertensives & $3,914(34)$ & $6,270(6)$ \\
\hline Other cardiovascular drugs* & $1,096(10)$ & $4,779(4)$ \\
\hline Antidiabetic drugs & $808(7)$ & \\
\hline
\end{tabular}

SD: standard deviation; ${ }^{1}$ In the 12 months before cohort entry; ${ }^{2}$ Results on prior drug use differ significantly between patients with breast cancer and their cancer-free controls $(p<0.0001) ;{ }^{*}$ Other cardiovascular drugs, such as antiarrhytmics, vasodilators and vasoprotectives. boembolic event and expressed with accompanying 95\% confidence intervals (CI). Conditional logistic regression was used to calculate odds ratios (OR) with 95\% CI. For patients with five year history in the PHARMO RLS sensitivity analyses were performed including prevalence proportions in five years before cohort entry. For incidence calculations, patients with a previous event (i.e. MI, ischaemic stroke or PE in the 12 months prior to cohort entry) were removed from the at-risk population for that specific event. Incidence rates per 1,000 person-years with accompanying 95\% CI based on Byar's approximation(22) were calculated for the three distinct periods of follow-up time. Cox proportional hazards regression analysis was used to compare the incidence of the thromboembolic events between breast cancer patients and their cancerfree controls including correction for possible confounders. To visualise the time course of PE among breast cancer patients the proportion of patients with PE (including $95 \% \mathrm{CI}$ ) was determined at 0-6 and 6-12 months before breast cancer hospitalisation and 0-6 and 6-12 months after breast cancer hospitalisation among patients with complete follow-up during these four periods. Cox proportional hazards regression models were also fit to identify independent risk factors for developing $\mathrm{MI}$, ischaemic stroke or PE in the complete follow-up after hospitalisation for breast cancer. The above mentioned patient characteristics were considered as potential risk factors. All risk factors associated with the outcome in the univariate analyses were included in the multivariate analyses. Statistical significance was defined at an alpha level of 0.05. Data were analysed using SAS (SAS Institute Inc., Cary, NC, USA).

\section{Results}

A total of 11,473 women with a first hospitalisation for breast cancer during 20002007 was selected from the PHARMO RLS and matched to 114,730 cancer-free women. Mean ( \pm standard deviation: SD) age of patients was $59( \pm 14)$ years. The mean $( \pm S D)$ duration of follow-up was $3.7( \pm 2.2)$ years for breast cancer patients and $3.9( \pm 2.2)$ years for the cancer-free controls. Use of the various types of cardiovascular drugs and antidiabetic drugs prior to breast cancer hospitalisation as presented in Table 1 was significantly higher among breast cancer patients compared to their cancer-free controls $(\mathrm{p}<0.0001)$. Similar use of these drugs was found during the first six months after breast cancer hospitalisation (data not shown). Of the breast cancer patients, $20 \%$ received chemotherapy, 32\% received antineoplastic hormonal therapy and $92 \%$ received breast cancer-related surgery during or within six months after the first breast cancer hospitalisation. Data on radiation therapy was not available in the PHARMO RLS. Median duration of breast cancer hospitalisation at cohort entry was 2 days (interquartile range $=1-5$ days).

Table 2 presents the proportion of patients with MI, ischaemic stroke or PE in the 12 months before breast cancer hospitalisation compared to cancer-free controls. Breast cancer patients were three times as likely as their cancer-free controls to have had a MI or PE and two times as likely to have had an ischaemic stroke. However, frequency of events was low: less than $1 \%$ in both the breast cancer cohort and their cancer-free controls. Sensitivity
Table 2: Proportion of patients with MI, ischaemic stroke or PE 12 months before breast cancer hospitalisation, compared to a non-cancer population.

\begin{tabular}{|c|c|c|c|c|c|}
\hline & \multicolumn{2}{|c|}{$\begin{array}{l}\text { Patients with breast cancer } \\
(\mathrm{N}=11,473)\end{array}$} & \multicolumn{2}{|c|}{$\begin{array}{l}\text { Cancer-free control cohort } \\
(\mathrm{N}=114,730)\end{array}$} & \multirow{2}{*}{$\begin{array}{l}\text { Odds ratio } \\
\text { (OR) } \\
(95 \% \mathrm{Cl})\end{array}$} \\
\hline & $\mathrm{N}$ & $\%(95 \% \mathrm{CI})$ & $\mathrm{N}$ & $\%(95 \% \mathrm{Cl})$ & \\
\hline Myocardial infarction & 32 & $0.28(0.19-0.39)$ & 112 & $0.10(0.08-0.12)$ & $2.9(1.9-4.2)$ \\
\hline Ischaemic stroke & 15 & $0.13(0.07-0.22)$ & 85 & $0.07(0.06-0.09)$ & $1.8(1.0-3.1)$ \\
\hline Pulmonary embolism & 11 & $0.10(0.05-0.17)$ & 33 & $0.03(0.02-0.04)$ & $3.4(1.7-6.7)$ \\
\hline
\end{tabular}


Table 3: Incidence rates of MI, ischaemic stroke or PE during three periods of follow-up since breast cancer hospitalisation, compared to a noncancer population.

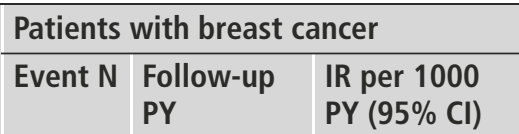

\begin{tabular}{|l|l|l|}
\multicolumn{3}{|c|}{ Cancer-free control cohort } \\
\hline Event N & $\begin{array}{l}\text { Follow-up } \\
\text { PY }\end{array}$ & $\begin{array}{l}\text { IR per } 1000 \\
\text { PY }(95 \% \mathrm{Cl})\end{array}$ \\
\hline
\end{tabular}

\begin{tabular}{|c|c|c|c|c|c|c|c|c|}
\hline \multicolumn{9}{|c|}{0 to 6 months after breast cancer hospitalisation } \\
\hline Myocardial infarction & 9 & 5,497 & $1.6(0.7-3.1)$ & 75 & 55,559 & $1.3(1.1-1.7)$ & $1.2(0.6-2.5)$ & $1.0(0.5-2.0)$ \\
\hline Ischaemic stroke & 8 & 5,505 & $1.5(0.5-2.9)$ & 46 & 55,580 & $0.8(0.6-1.1)$ & $1.8(0.8-3.8)$ & $1.1(0.5-2.5)$ \\
\hline Pulmonary embolism & 26 & 5,506 & $4.7(3.1-6.9)$ & 16 & 55,610 & $0.3(0.2-0.5)$ & $17.3(9.2-32.6)$ & $23.5(11.1-49.7)$ \\
\hline \multicolumn{9}{|c|}{6 to 12 months after breast cancer hospitalisation } \\
\hline Myocardial infarction & 8 & 5,082 & $1.6(0.6-3.1)$ & 60 & 51,695 & $1.2(0.9-1.5)$ & $1.4(0.7-3.0)$ & $1.5(0.7-3.1)$ \\
\hline Ischaemic stroke & 9 & 5,089 & $1.8(0.8-3.3)$ & 39 & 51,730 & $0.8(0.5-1.0)$ & $2.4(1.1-4.9)$ & $1.8(0.8-3.9)$ \\
\hline Pulmonary embolism & 14 & 5,085 & $2.8(1.6-4.5)$ & 15 & 51,765 & $0.3(0.2-0.5)$ & $9.2(4.4-19.1)$ & $9.0(4.2-19.5)$ \\
\hline \multicolumn{9}{|c|}{12 months to total follow-up after breast cancer hospitalisation } \\
\hline Myocardial infarction & 55 & 31,360 & $1.8(1.3-2.3)$ & 404 & 334,133 & $1.2(1.1-1.3)$ & $1.5(1.1-2.0)$ & $1.3(1.0-1.7)$ \\
\hline Ischaemic stroke & 50 & 31,438 & $1.6(1.2-2.1)$ & 349 & 334,624 & $1.0(0.9-1.2)$ & $1.5(1.1-2.1)$ & $1.2(0.9-1.6)$ \\
\hline Pulmonary embolism & 31 & 31,430 & $1.0(0.7-1.4)$ & 93 & 335,363 & $0.3(0.2-0.3)$ & $3.6(2.4-5.4)$ & $3.6(2.4-5.5)$ \\
\hline
\end{tabular}

PY: person years; IR: incidence rate; $95 \% \mathrm{Cl}$ : 95\% confidence interval; \# hazard ratio for myocardial infarction adjusted for prior use of antithrombotic drugs, lipidlowering drugs and antihypertensive drugs. Hazard ratio for ischaemic stroke adjusted for prior use of antithrombotic drugs, lipid-lowering drugs, antihypertensive drugs and other cardiovascular drugs. Hazard ratio for pulmonary embolism adjusted for prior use of antithrombotic drugs, lipid-lowering drugs and other cardiovascular drugs.

analysis including proportions over a period of five years before cohort entry showed similar results, with $\mathrm{OR}=1.8$ (95\%CI: 1.3-2.6) for MI, OR=1.7 (95\%CI: 1.1-2.5) for ischaemic stroke and $\mathrm{OR}=3.0(95 \% \mathrm{CI}: 1.7-5.1)$ for PE.

Incidence rates of MI, ischaemic stroke or PE are presented for three distinct periods of follow-up time (Table 3). The incidence of MI and ischaemic stroke among hospitalised breast cancer patients ranged from 1.5 to 1.8 per 1,000 person years (py) for the various follow-up periods. Compared to the cancer-free control cohort after correction for possible confounders, the hazard ratio (HR) for MI was 1.0 (95\%CI: 0.5-2.0) in 0-6 months, 1.5 (95\%CI: $0.7-3.1)$ in 6-12 months and $1.3(95 \%$ CI: $1.0-1.7)$ in 12 months to total follow-up. For ischaemic stroke these were 1.1 (95\%CI: 0.5-2.5), 1.8 (95\%CI: 0.8-3.9) and 1.2 (95\% CI: 0.9-1.6), respectively. In contrast, the incidence of PE decreased over time from 4.7 per 1,000 py in $0-6$ months after breast cancer hospitalisation, to 1.0 per 1,000 py in 12 months to total follow-up. Compared to the controls, the risk of PE was largely increased, especially shortly after hospitalisation. In the first six months, the adjusted HR was 23.5 (95\%CI: 11.1-49.7), while the HR was 9.0 (95\%CI: 4.2-19.5) between 6-12 months, and 3.6 (95\%CI: 2.4-5.5) 12 months and later after breast cancer hospitalisation. This change in the proportion of breast cancer patients with PE over time is visualised in - Figure 1. The proportion of patients with PE increased over time before breast cancer diagnosis, with the highest peak directly after diagnosis and a decrease thereafter.

Multivariate analyses in Table 4 show that independent risk factors for developing MI in the complete follow-up after hospitalisation for breast cancer were: older age ( $\geq 70$ years vs. $\leq 49$ years;
$\mathrm{HR}=5.9$; 95\%CI: 2.0-17.2), prior use of antihypertensives ( $\mathrm{HR}=1.6$; 95\%CI: 1.0-2.8) and cumulative duration of hospital stay longer than 10 days (irrespective of type of hospitalisation) during the first six months of follow-up ( $\mathrm{HR}=1.6$; 95\%CI: 1.0-2.6). Independent risk factors for developing ischaemic stroke were: older age ( $\geq 70$ years vs. $\leq 49$ years; $\mathrm{HR}=5.8 ; 95 \%$ CI: $1.7-20.0$ ) and prior use of platelet aggregation inhibitors (HR=1.9; 95\%CI: 1.1-3.4), antihypertensives (HR=2.6; 95\%CI: 1.4-4.8) or antidiabetic drugs (HR=2.4; 95\% CI: 1.3-4.3). Independent risk factors for developing PE in complete follow-up after correction for other risk factors were: older age ( $\geq 70$ years vs. $\leq 49$ years; $H R=3.0$; 95\%CI: 1.3-6.7), use of chemotherapy (HR=2.4; 95\%CI: 1.3-4.5) or antineoplastic hormonal therapy ( $\mathrm{HR}=2.1 ; 95 \% \mathrm{CI}: 1.3-3.4)$ and total hospital stay $>10$ days $(\mathrm{HR}=2.6$; $95 \% \mathrm{CI}$ : 1.6-4.3) during the first six months of follow-up.

\section{Discussion}

Our large population-based study showed that the proportion of breast cancer patients hospitalised for PE changed remarkably over time. Breast cancer patients were three times as likely as their cancer-free controls to have had a hospitalisation for PEin the 12 months before breast cancer diagnosis. Directly after breast cancer hospitalisation a 24-fold, significant increased risk for PE was found and this risk declined gradually to a four times increased risk for thromboembolism more than 12 months after breast cancer hospitalisation. Regarding arterial thromboembolism, breast 
Figure 1: Patients with $\mathrm{PE}$ (including $95 \% \mathrm{Cls}$ ) in the 12 months before and 12 months after breast cancer hospitalisation.

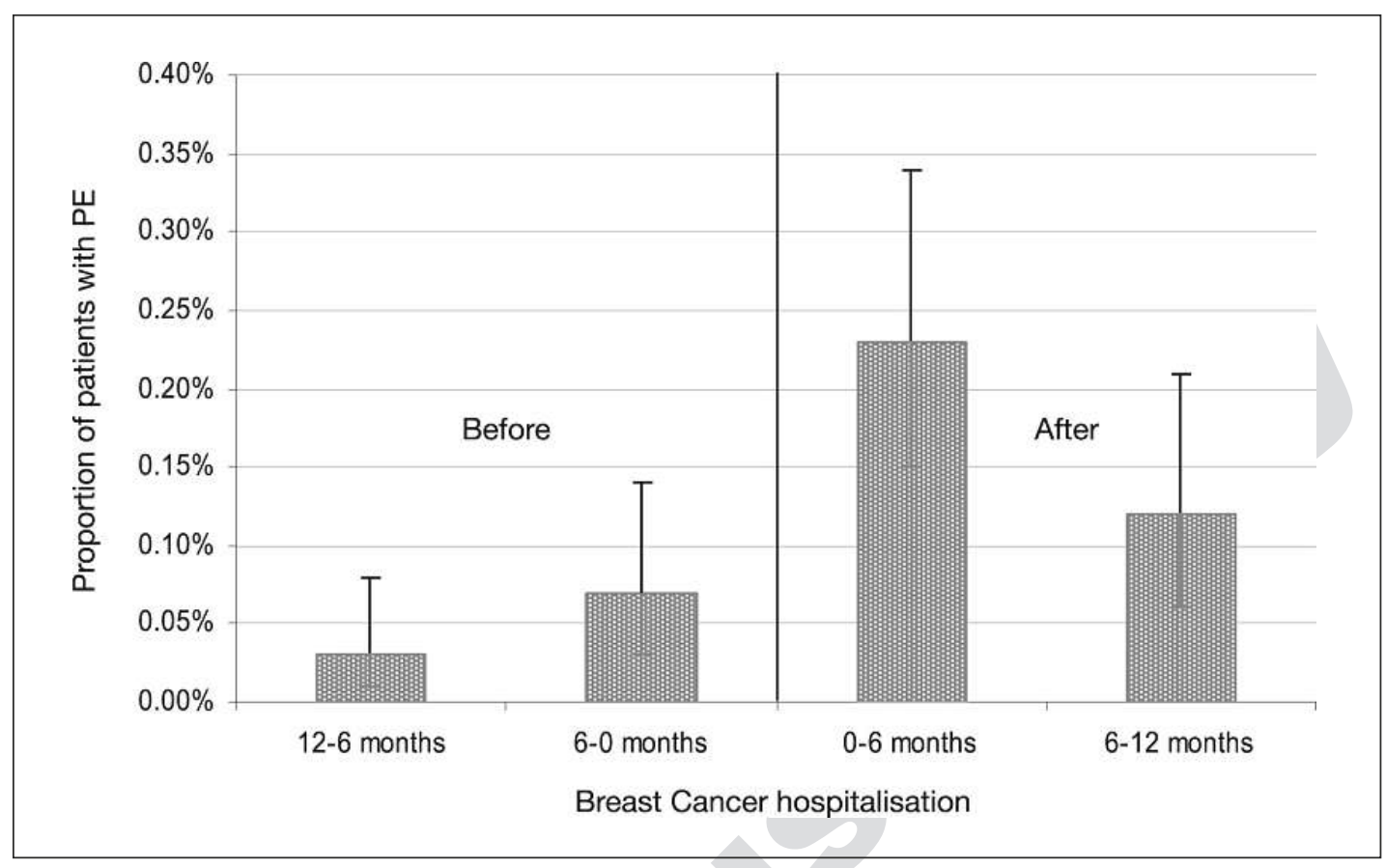

Table 4: Risk factors for developing MI, ischaemic stroke or PE after hospitalisation for breast cancer.

\begin{tabular}{|c|c|c|c|c|c|c|}
\hline \multirow[t]{2}{*}{ Characteristics } & \multicolumn{2}{|c|}{ Myocardial infarction } & \multicolumn{2}{|l|}{ Ischaemic stroke } & \multicolumn{2}{|c|}{ Pulmonary embolism } \\
\hline & HR Multivariate \# & $95 \% \mathrm{Cl}$ & HR Multivariate \# & $95 \% \mathrm{Cl}$ & HR Multivariate \# & $95 \% \mathrm{Cl}$ \\
\hline \multicolumn{7}{|l|}{ Age at diagnosis } \\
\hline$\leq 49$ years & 1 & reference & 1 & reference & 1 & reference \\
\hline $50-69$ years & 3.5 & $(1.2-9.9)$ & 2.5 & $(0.7-8.6)$ & 2.3 & $(1.1-4.6)$ \\
\hline$\geq 70$ years & 5.9 & $(2.0-17.2)$ & 5.8 & $(1.7-20.0)$ & 3.0 & $(1.3-6.7)$ \\
\hline \multicolumn{7}{|l|}{ Prior drug use* } \\
\hline Platelet aggregation inhibitors & 1.5 & $(0.8-2.7)$ & 1.9 & $(1.1-3.4)$ & & \\
\hline Other antithrombotic drugs & & & 1.6 & $(0.8-3.4)$ & & \\
\hline Lipid-lowering drugs & 1.2 & $(0.6-2.2)$ & 0.7 & $(0.4-1.5)$ & & \\
\hline Antihypertensives & 1.6 & $(1.0-2.8)$ & 2.6 & $(1.4-4.8)$ & & \\
\hline Other cardiovascular drugs ** & 1.0 & $(0.5-1.8)$ & 1.0 & $(0.5-1.9)$ & & \\
\hline Antidiabetic drugs & 1.7 & $(0.9-3.2)$ & 2.4 & $(1.3-4.3)$ & & \\
\hline \multicolumn{7}{|l|}{ Treatment§ } \\
\hline Chemotherapy & & & & & 2.4 & $(1.3-4.5)$ \\
\hline Antineoplastic hormonal therapy & & & & & 2.1 & $(1.3-3.4)$ \\
\hline \multicolumn{7}{|c|}{ Duration of any hospitalisation§ } \\
\hline $0-10$ days & 1 & reference & & & 1 & reference \\
\hline$>10$ days & 1.6 & $(1.0-2.6)$ & & & 2.6 & $(1.6-4.3)$ \\
\hline
\end{tabular}


cancer patients were three times as likely to have had a MI and two times as likely as to have had an ischaemic stroke before breast cancer hospitalisation compared to their cancer-free controls, but we did not observe a significantly increased HR after breast cancer hospitalisation.

Similar proportions of VTE before breast cancer diagnosis, i.e. $0.06 \%-0.1 \%$, were found in previous studies $(10,12)$. However, in the study of White et al., VTE rates before breast cancer diagnosis among patients registered in the California Cancer registry were similar to the age-, race- and sex-specific rates in California (12). A higher incidence of PE in the first six months after breast cancer hospitalisation and decrease in the periods afterwards was also found by Chew et al. who reported 1.2 events of venous thrombosis per 100 py during the first half-year and 0.6 per 100 py during the second half-year of follow-up (11). When taking into account that in the study of Chew et al. both deep-vein thrombosis (DVT) and PE were included and that the former occurs two to three times more often than the latter $(6,7)$, these incidences of venous thrombosis are similar to ours: 4.7 per 1,000 py in the first half-year and 2.8 per 1,000 py in the second half-year after breast cancer hospitalisation. Chew et al. also found a four-fold higher risk of VTE among breast cancer patients in the first year after breast cancer diagnosis compared with the general population.(11)

The increased rate of PE before breast cancer hospitalisation might be caused by the presence of occult cancer $(23,24)$. The increased risk of PE directly after breast cancer hospitalisation can be explained by the cancer itself and its related treatment, including surgery, chemotherapy, radiotherapy, or hormone therapy and immobilisation following treatment $(3,4,13)$. The low proportion of patients using antithrombotic drugs in the first six months after breast cancer hospitalisation (16\%) suggests that patients often did not receive thromboprophylaxis after breast cancer hospitalisation. Independent risk factors for developing PE in complete follow-up after correction for other risk factors were: older age and

\section{What is known about this topic?}

- Cancer patients are at increased risk for thromboembolic complications compared to cancer-free controls.

- While the rate of venous thromboembolism among cancer patients has been determined in several retrospective cohort studies, less is known about the incidence of both venous and arterial thrombosis and the timing of these events.

\section{What does this paper add?}

- Compared to cancer-free controls, breast cancer patients are at increased risk to develop pulmonary embolism, with the highest risk directly after diagnosis and a decrease thereafter.

- Breast cancer patients seem to have a higher risk profile to develop myocardial infarction or ischaemic stroke compared to cancerfree controls.

- The incidence of hospitalisation for myocardial infarction, ischaemic stroke or pulmonary embolism in breast cancer patients is low $(<1 \%)$. breast cancer treatment-related factors: use of chemotherapy or antineoplastic hormonal therapy and total hospital stay of more than 10 days during the first six months of follow-up. To our knowledge, there are no previous studies reporting risk factors for only $\mathrm{PE}$ among breast cancer patients. One study reported the following risk factors for developing venous thrombosis, including PE as well as DVT, within two years after breast cancer diagnosis: age, the number of chronic co-morbidities and advancing cancer stage (11). Other studies among various types of cancer found that next to cancer site, the following factors influence the risk of cancer-associated thrombosis: tumour stage, age, gender, co-morbidities (e.g. hypertension, diabetes, obesity and hyperlipidaemia) and cancer treatment (e.g. surgery, radiation therapy, chemotherapy and hormonal therapy) $(6,13,25)$.

Regarding arterial thrombotic events, our data suggest that women developing breast cancer are more likely to suffer from cardiovascular co-morbidity: rates of arterial thrombosis before breast cancer diagnosis as well as prior cardiovascular drug use were higher among breast cancer patients than their cancer-free controls. This might be explained by the fact that arterial thromboembolism and breast cancer share similar risk factors such as obesity $(26,27)$.

The rate of arterial thrombotic events did not change over time after breast cancer hospitalisation. Risk factors for developing MI or ischaemic stroke were prior use of cardiovascular drugs, while chemotherapy or hormonal therapy in the first six months after breast cancer hospitalisation were not significantly related to the risk of developing MI or ischaemic stroke. This might be due to the fact that patients are treated less aggressively when cardiovascular co-morbidities are present $(28,29)$; therefore, the increased risk of arterial thrombosis after chemotherapy, or antineoplastic hormonal therapies which is seen in other studies (30-33), was not seen in our study.

Our study has some limitations that need to be discussed. First of all, we used a hospitalisation database to identify venous and arterial thromboembolic events. Using an administrative database to define these events is less accurate than clinical chart review. However, we included in our study only the more serious and well-defined venous and arterial thromboembolic events that lead to a hospitalisation (17-21). We did not include e.g. DVT as many of these patients might be treated outside the hospital (34), resulting in an underestimation of the incidence of DVT when using hospitalisation data. Another limitation is that we were not able to include risk factors such as tumour stage, radiation therapy, obesity, positive family history of coronary artery disease, cigarette smoking and increased psychological distress, as these were not recorded in the used databases. We could have retrieved data on tumour stage and radiation therapy for a subset of patients (35). However, as the incidence of thromboembolism among breast cancer patients is low, the sample size was too small to study these risk factors for MI, ischaemic stroke and PE separately. Furthermore, our population was restricted to patients hospitalised for breast cancer. Validation of a sub-cohort by linking the PHARMO RLS and the Eindhoven Cancer Registry(35) showed more than $95 \%$ of the patients diagnosed with breast cancer in the Netherlands to have been 
hospitalised. The small proportion of patients that are not hospitalised and therefore not in our current study population are more likely to be 80 years or older, have metastatic breast cancer and institutionalised.

To achieve optimal treatment and prognosis among breast cancer patients, this study contributes to the awareness of the incidence of thromboembolic events among breast cancer patients and the risk factors and risk periods of thrombosis. Breast cancer patients seem to have a higher risk profile to develop arterial thromboembolism and receive treatment that increases the risk of VTE. However, incidence of hospitalisations for MI, ischaemic stroke and PE was low.

\section{Conflict of interest}

No conflict of interest is declared for Dr. PW Kamphuisen. Mrs. MPP van Herk-Sukel, Dr. FJA Penning-van Beest and Dr. RMC Herings are employees of the PHARMO Institute for Drug Outcomes Research. This research institute performs financially supported studies for several pharmaceutical companies. Dr. S Shantakumar is an employee of GlaxoSmithKline, RTP, NC, USA and holds GlaxoSmithKline shares.

\section{References}

1. Buller HR, van Doormaal FF, van Sluis GL, et al. Cancer and thrombosis: from molecular mechanisms to clinical presentations. J Thromb Haemost 2007; 5 (Suppl 1): 246-254.

2. Khorana AA. Cancer and thrombosis: implications of published guidelines for clinical practice. Ann Oncol 2009; 20: 1619-1630.

3. Prandoni P, Falanga A, Piccioli A. Cancer and venous thromboembolism. Lancet Oncol 2005; 6: 401-410.

4. Heit JA, Silverstein MD, Mohr DN, et al. Risk factors for deep vein thrombosis and pulmonary embolism: a population-based case-control study. Arch Intern Med 2000; 160: 809-815.

5. Khorana AA, Connolly GC. Assessing risk of venous thromboembolism in the patient with cancer. J Clin Oncol 2009; 27: 4839-4847.

6. Khorana AA, Francis CW, Culakova E, et al. Frequency, risk factors, and trends for venous thromboembolism among hospitalized cancer patients. Cancer 2007; 110: 2339-2346.

7. Stein PD, Beemath A, Meyers FA, et al. Incidence of venous thromboembolism in patients hospitalized with cancer. Am J Med 2006; 119: 60-68.

8. Chew HK, Wun T, Harvey D, et al. Incidence of venous thromboembolism and its effect on survival among patients with common cancers. Arch Intern Med 2006; 166: 458-464.

9. Kuderer NM, Ortel TL, Francis CW. Impact of venous thromboembolism and anticoagulation on cancer and cancer survival. J Clin Oncol 2009; 27:4902-4911.

10. Blom JW, Vanderschoot JP, Oostindier MJ, et al. Incidence of venous thrombosis in a large cohort of 66,329 cancer patients: results of a record linkage study. J Thromb Haemost 2006; 4: 529-535.

11. Chew HK, Wun T, Harvey DJ, et al. Incidence of venous thromboembolism and the impact on survival in breast cancer patients. J Clin Oncol 2007; 25: 70-76.

12. White RH, Chew HK, Zhou H, et al. Incidence of venous thromboembolism in the year before the diagnosis of cancer in 528,693 adults. Arch Intern Med 2005; 165 : $1782-1787$.
13. Di Nisio M, Ferrante N, De Tursi M, et al. Incidental venous thromboembolism in ambulatory cancer patients receiving chemotherapy. Thromb Haemost 2010; 104: 1049-1054.

14. Paneesha S, McManus A, Arya R, et al. Frequency, demographics and risk (according to tumour type or site) of cancer-associated thrombosis among patients seen at outpatient DVT clinics. Thromb Haemost 2010; 103: 338-343.

15. Javid M, Magee TR, Galland RB. Arterial thrombosis associated with malignant disease. Eur J Vasc Endovasc Surg 2008; 35: 84-87.

16. Dutch Hospital Data. Available at: http://www.dutchhospitaldata.nl.

17. So L, Evans D, Quan H. ICD-10 coding algorithms for defining comorbidities of acute myocardial infarction. BMC Health Serv Res 2006; 6: 161.

18. Roumie CL, Mitchel E, Gideon PS, et al. Validation of ICD-9 codes with a high positive predictive value for incident strokes resulting in hospitalization using Medicaid health data. Pharmacoepidemiol Drug Saf 2008; 17: 20-26.

19. Wolinsky FD, Wan GJ, Gurney JG, et al. The risk of hospitalization for ischemic stroke among older adults. Med Care 1998; 36: 449-461.

20. Horlander KT, Mannino DM, Leeper KV. Pulmonary embolism mortality in the United States, 1979-1998: an analysis using multiple-cause mortality data. Arch Intern Med 2003; 163: 1711-1717.

21. Kniffin WD, Jr., Baron JA, Barrett J, et al. The epidemiology of diagnosed pulmonary embolism and deep venous thrombosis in the elderly. Arch Intern Med 1994; 154: 861-866.

22. Breslow NE, Day NE. Statistical methods in cancer research, Volume II: The design and analysis of cohort studies. Lyon: IARC Scientific Publications No. 82; 1989. pp. 69-72.

23. Otten HM, Prins MH. Venous thromboembolism and occult malignancy. Thromb Res 2001; 102: V187-194.

24. Piccioli A, Prandoni P. Venous thromboembolism as first manifestation of cancer. Acta Haematol 2001; 106: 13-17.

25. Blom JW, Doggen CJ, Osanto S, et al. Malignancies, prothrombotic mutations, and the risk of venous thrombosis. J Am Med Assoc 2005; 293: 715-722.

26. Trentham-Dietz A, Newcomb PA, Egan KM, et al. Weight change and risk of postmenopausal breast cancer (United States). Cancer Causes Control 2000; 11: 533-542.

27. Manson JE, Colditz GA, Stampfer MJ, et al. A prospective study of obesity and risk of coronary heart disease in women. N Engl J Med 1990; 322: 882-889.

28. Janssen-Heijnen ML, Szerencsi K, van de Schans SA, et al. Cancer patients with cardiovascular disease have survival rates comparable to cancer patients within the age-cohort of 10 years older without cardiovascular morbidity. Crit Rev Oncol Hematol 2010; 76: 196-207.

29. Sukel MP, Breekveldt-Postma NS, Erkens JA, et al. Incidence of cardiovascular events in breast cancer patients receiving chemotherapy in clinical practice. Pharmacoepidemiol Drug Saf 2008; 17: 125-134.

30. Jones LW, Haykowsky MJ, Swartz JJ, et al. Early breast cancer therapy and cardiovascular injury. J Am Coll Cardiol 2007; 50: 1435-1441.

31. Lenihan DJ, Esteva FJ. Multidisciplinary strategy for managing cardiovascular risks when treating patients with early breast cancer. Oncologist 2008; 13: 1224-1234.

32. McDonald CC, Alexander FE, Whyte BW, et al. Cardiac and vascular morbidity in women receiving adjuvant tamoxifen for breast cancer in a randomised trial. The Scottish Cancer Trials Breast Group. Br Med J 1995; 311: 977-980.

33. Saphner T, Tormey DC, Gray R. Venous and arterial thrombosis in patients who received adjuvant therapy for breast cancer. J Clin Oncol 1991; 9: 286-294.

34. Zidane M, van Hulsteijn LH, Brenninkmeijer BJ, et al. Out of hospital treatment with subcutaneous low molecular weight heparin in patients with acute deepvein thrombosis: a prospective study in daily practice. Haematologica 2006; 91: 1052-1058.

35. van Herk-Sukel MP, van de Poll-Franse LV, Lemmens VE, et al. New opportunities for drug outcomes research in cancer patients: The linkage of the Eindhoven Cancer Registry and the PHARMO Record Linkage System. Eur J Cancer 2010; 46: 395-404. 